\title{
Fatores de atratividade e retenção de profissionais altamente qualificados em cidades
}

Anderson Da Cunha Jesus ${ }^{1}$

Yeda Swirski De Souza ${ }^{1}$

${ }^{1}$ Universidade do Vale do Rio dos Sinos 


\section{FATORES DE ATRATIVIDADE E RETENÇÃO DE PROFISSIONAIS ALTAMENTE QUALIFICADOS EM CIDADES}

Resumo: As cidades representam um contexto privilegiado para a convergência entre tecnologia, tendências de estilo de vida, atividades culturais e o surgimento espontâneo de grupos de inovação e empreendedorismo. Por meio de uma revisão sistemática da literatura, este artigo analisa fatores de atratividade e retenção de profissionais altamente qualificados em cidades e contribui com a definição de uma análise integrada sobre fatores de atratividade urbana para esses profissionais. Utilizam-se conceitos de capital humano e mobilidade, pois se mostram bases teóricas pertinentes ao comportamento dos profissionais com alta qualificação e são propostas categorias de fatores de atratividade urbana para esses profissionais. As categorias envolvem tolerância social, qualidade de vida, ambiente de empreendedorismo e inovação e educação. Os estudos no tema predominam em ambientes europeus. Pesquisas futuras poderiam aplicar esta análise integradora para verificar sua pertinência em outros contextos específicos, como ambientes urbanos de países em desenvolvimento.

Palavras-chave: Cidades. Mobilidade. Capital humano. Empreendedorismo.

\section{Introdução}

Em uma economia baseada em conhecimento, as cidades ocupam um papel essencial. Qualidade de vida, intensidade cultural, mobilidade, diversidade, inclusão, entre outros aspectos, revelam-se cruciais na atratividade de profissionais e empreendedores com qualificações para alavancar atividades que demandam conhecimento, criação e inovação. Nesse contexto, esta pesquisa examina fatores de atratividade e retenção de profissionais altamente qualificados em cidades e tem por objetivo contribuir com a proposição de um modelo integrador sobre fatores de atratividade urbana para esses profissionais.

Davenport (2005) argumenta que os trabalhadores do conhecimento são aqueles que possuem alto grau de conhecimento profissional e de educação, sendo que a criação e transferência de conhecimento estão no coração de suas atividades de trabalho. Na literatura, muitos termos são usados para tratar de profissionais intensivos em conhecimento, contendo diferenças e similaridades entre si, tais como especialistas, experts, gestores, trabalhadores da informação e profissionais Science, Technology, Engineering and Mathematics - STEM (SURAWSKI, 2019; BREINER et. al., 2012). Neste artigo, será utilizada a nomenclatura de profissionais altamente qualificados para contemplar esses termos e o interesse de estudo da pesquisa.

Diferentes abordagens em estudos acadêmicos contribuem para a análise do problema da atratividade e retenção de talentos em cidades. Os estudos sobre a posição das cidades na economia baseada em conhecimento (SASSEN, 1999; SHAPIRO, 2006; THITE, 2011) e os conceitos de capital humano (BECKER, 1962; SCHULTZ, 1961) e sua mobilidade (SAXENIAN, 2005; BIAO, 2011) constituem, aqui, a base teórica para o entendimento das 
relações entre as cidades e os profissionais altamente qualificados. A teoria do capital humano é explicativa para a mobilidade já que a formação, conhecimento e expertise impactam positivamente a mobilidade interna e externa de profissionais (BECKER, 1962; FELSESTEIN, 2015).

Além disso, não só organizações, mas também cidades e regiões estão competindo por abrigar talentos que movem a economia baseada em conhecimento (THITE, 2011). Esses profissionais exercem sua atuação em contextos urbanos e com alta conectividade provida pela tecnologia. Em seu comportamento, migram não somente em busca de bons empregos, mas em busca de qualidade de vida e de outros elementos que são encontrados em uma vida urbana (NIKOLOPOULOS; DANA, 2017). Entender quais são esses elementos é de suma importância para cidades, regiões e organizações intensivas em conhecimento. Sassen (2009) aponta que essa mistura de talentos, expertise e empresas intensivas em conhecimento fazem da cidade um centro complexo de troca de informações.

Assim, cidades e regiões que buscam desenvolvimento em uma economia do conhecimento e criativa demandam práticas, políticas, mecanismos e cultura que contribuam para a concentração desses trabalhadores. Apesar da importância dos estudos nessa temática, observa-se que há uma variedade de diferentes fatores locais de atratividade sendo utilizados nos estudos acadêmicos (ACS e MEGIESY, 2009; RAO e DAI, 2017; SZCZECH, 2014; CHAPAIN e COMUNIAN, 2010; LORENZEN e ANDERSEN, 2012), sem haver, entretanto, integração entre eles.

Esta pesquisa descreve que existe alternância nos fatores utilizados pela comunidade acadêmica neste tema. A falta de integração entre as pesquisas no tema apontam para a necessidade de novos estudos sobre fatores explicativos para a atratividade e retenção de profissionais altamente qualificados em cidades.

Contribui-se teoricamente para o campo de estudos sobre mobilidade de capital humano, à medida que busca integrar resultados de trabalhos que se ocupam em entender quais são os fatores de atratividade e retenção local de profissionais que tem no conhecimento o seu grande objeto de atuação. O estudo também contribui com gestores e formuladores de políticas públicas para espaços urbanos, uma vez que elucida o quanto determinados fatores podem ser relevantes para esses locais. Além disso, a temática deste estudo é objeto de interesses de pesquisas de diferentes campos, tais como gestão e negócios, geografia humana, sociologia e planejamento urbano.

Este artigo está estruturado da seguinte forma: a próxima seção apresenta o referencial teórico que sustenta a pesquisa, abordando os temas das cidades na economia baseada em conhecimento, da mobilidade de capital humano e de brain circulation. A seção seguinte descreve os procedimentos metodológicos da pesquisa. Por fim, nos resultados há a apresentação de um quadro integrador com a proposição de categorias de fatores de atratividade e suas análises. E nas considerações finais, as conclusões, limitações da pesquisa e sugestões de estudos futuros. 


\section{Referencial teórico}

\subsection{Cidades na economia baseada em conhecimento}

Engel et. al. (2018) destacam que, ao longo da história da humanidade, as cidades tem sido centros de produção, comércio e inovação que emergem de novos mercados, cruzamentos de ideias e culturas. Já no século XXI, influenciadas por uma economia globalizada e dinâmica, as cidades competem por atrair profissionais altamente qualificados e investimentos que contribuam para um engajamento local e uma competitividade global.

As cidades da nova economia desempenham um papel crucial na distribuição global de profissionais com capital humano altamente qualificado. Elas estão interligadas por redes globais (CASTELLS, 1999) e, apesar de distantes fisicamente, estão conectadas pelo poder das tecnologias de informação, causando um cenário jamais visto anteriormente pela humanidade (SASSEN, 1999).

Thite (2011) argumenta que no século XXI, as áreas metropolitanas - e não os estados-nação - é que moldarão as agendas sociais, culturais, tecnológicas e econômicas do mundo. Esse processo leva a uma competição cada vez maior por recursos intelectuais e materiais, mas também força as cidades a cooperarem e aprenderem umas com as outras. $\mathrm{O}$ nexo de vantagem competitiva mudou para as cidades e regiões que podem gerar, reter e atrair os melhores talentos para o seu desenvolvimento. Florida (2012) ainda relata que neste século uma cidade competitiva será aquela que for atraente, na qual todas as classes de talentos humanos vão querer se reunir e aglomerar. Assim, gestores urbanos e autoridades estão deliberando sobre reconstruir os conceitos de suas cidades para atrair todos os tipos de talentos desejáveis.

Sassen (2009) estudou as tendências que criaram a aglomeração das cidades. Novas tecnologias de comunicação, transporte e Internet explicam a concentração urbana na era atual. Dessas tecnologias surgem questões como o teletrabalho em escritórios urbanos, que podem produzir um movimento de pessoas do centro para a periferia. Na direção oposta, essas instalações de gerenciamento remoto permitem que empresas possam expandir suas atividades em outras cidades distantes, buscando novos mercados e pessoas especializadas. Em suma, quanto mais poderosas são as novas tecnologias, maior é a capacidade de gerenciamento a distância; portanto, é mais fácil estender as operações globalmente, criando novos centros de densidade e centralidade urbana.

As forças da globalização tornaram possível que os talentos pudessem fazer escolhas de dispersão e de busca pelas melhores oportunidades e condições de vida. Assim, a competição por esses trabalhadores é global (KHOO et. al., 2017). As empresas da economia do conhecimento operam a partir de polos de criatividade e inovação que usam as cidades como trampolim para executar negócios internacionais e buscar vantagem competitiva sustentável (SOFRONIJEVIC et. al., 2014). Nesse sentido, Thite (2011) argumenta que a vantagem competitiva das organizações na economia baseada em conhecimento não é mais um fator exclusivo ao interior das empresas, mas também à qualidade e atratividade da localidade em que se inserem. Ou seja, um setor intensivo em conhecimento aglomerado em uma localidade não atrativa para profissionais altamente qualificados tende a perder competitividade no mercado. Afinal, esses profissionais possuem mobilidade facilitada 
devido a sua alta formação e podem alargar suas fronteiras de oportunidades de trabalho no mundo globalizado.

As cidades tem ocupado um papel cada vez mais central no desenvolvimento global de talentos e na economia do conhecimento. Suas relevâncias social, econômica e política estão renovadas. Conforme as cidades crescem, vão ocupando um papel central e protagonista no mundo. E esse fato desencadeia desafios substanciais para governos de todos os níveis, os quais devem estar atentos para resolver os problemas das cidades (ROSA; SOUZA, 2018).

Entende-se que cidades tem potencial para estimular a criatividade e inovação, reduzir custos de transação e aumentar qualidade de vida devido sua dinâmica de interações pessoais diretas. (ASHEIM et. al., 2011; SHAPIRO, 2006; FLORIDA, 2012). Entretanto, nem tudo é perfeito quando se fala em cidades no século XXI. Um ponto relevante é que elas não foram preparadas para crescer tão rapidamente, o que acaba não só sufocando seus aspectos positivos como podendo torná-las locais duros de se viver (GIL-GARCIA et. al., 2015).

Engel et. al. (2018) sugerem que o rápido crescimento das cidades como clusters de inovação somente é sustentável se houver uma cultura de colaboração entre governo, academia, empresas, investidores e serviços públicos. Para esses autores, os governos deveriam fazer escolhas sobre onde os recursos devem ser investidos, dar suporte às incertezas e facilitar a coordenação entre público e privado. Ao direcionar a mudança, o objetivo maior dos governos locais deveria ser a criação de novos mercados e áreas de expansão de indústrias, para além de apenas controlar estes itens.

A conexão entre a densidade urbana e os ganhos econômicos é uma das principais razões pela qual as cidades existem (GLAESER; RESSEGER, 2010). Os autores argumentam que a densidade urbana facilita a aprendizagem de trabalhadores uns com os outros. Outra assunção é que altos níveis de capital humano e grandes cidades interagem para alavancar o nível de produtividade e empurrar as fronteiras do conhecimento. Inclusive, em seus estudos, os autores encontraram evidências de que profissionais aprendem mais rapidamente em áreas metropolitanas. Além disso, este efeito de aprendizagem é mais forte em áreas que abrigam maior número de profissionais altamente qualificados. Nas grandes áreas urbanas os profissionais aprendem mais rapidamente e a mudança tecnológica é cada vez mais veloz.

\subsection{Capital humano e mobilidade}

Os conceitos sobre o capital humano se desenvolveram ao longo de vários séculos, mas tomaram forma como uma teoria no Ocidente na década de 1960. São reconhecidas as contribuições da teoria do capital humano para a economia e a cultura. Esta teoria evoluiu com base na teoria do crescimento econômico ocidental e nos estudos sobre o comportamento humano. A teorização do capital humano foi promovida nas nações ocidentais e os resultados de pesquisas na área deram grandes contribuições para o desenvolvimento social, econômico e corporativo (ZHAO, 2008).

Há diversas definições sobre o conceito de capital humano. Em trabalhos seminais, Becker (1962) definiu o capital humano como conhecimento, ideias, habilidades, informação e saúde dos indivíduos. O capital humano não pode ser separado do indivíduo, o que lhe confere um caráter de unicidade. 
Schultz (1961), outro autor seminal, defende a ideia de que a maior forma de riqueza é a capacidade produtiva humana e que, inclusive, a superioridade de um país sobre outro deriva do investimento feito nas pessoas. Além disso, Becker (1962), imprimiu grandes esforços em ajudar a desenvolver uma teoria acerca dos investimentos no capital humano.

Zhao (2008) relata o que são considerados os principais pontos dessa teoria: (a) sua propriedade é inerente à pessoa. O capital humano pode ser naturalmente propriedade do indivíduo trabalhador. (b) Como propriedade dinâmica, o capital humano pode ser usado não pela exploração, mas pela motivação. (c) O capital humano pode ter um grande potencial de aproveitamento. (d) A teoria de alocação de capital humano, que envolve a questão de transferir e realocar capital humano em diferentes regiões ou setores.

Os investimentos em capital humano criam pessoas mais competentes e capazes, desenvolvem um capital estrutural melhor e leva ao desenvolvimento de capital externo mais produtivo. Somado a isso, resultam em melhor desempenho financeiro (TSENG e GOO, 2005). Neste sentido, o capital humano acumulado através da educação e da experiência serve como base para o desenvolvimento de capacidades e habilidades. As empresas constroem seu capital humano com remuneração competitiva para atrair e reter profissionais qualificados e experientes, além de investir em programas de treinamento para desenvolver capacidades e habilidades específicas (ONKELINX, MANOLOVA e EDELMAN, 2016).

A mobilidade de trabalhadores altamente qualificados está muito associada à capacidade de se transferir conhecimento em termos geográficos. Zagadi e Desai (2017) defendem que a mobilidade de talentos é um fenômeno global emergente e crescente, de proporções significativas e que afeta o progresso socioeconômico e sociocultural das sociedades do mundo todo. Em alguns países, essa circulação foi fomentada por uma política deliberada. Em outros, o fenômeno segue sem políticas regulatórias eficazes. A migração de profissionais dotados de capital humano elevado é marcada por vários dilemas fundamentais. Dentre eles, pode-se falar de imperativos políticos e éticos, como a tensão entre a liberdade individual e o controle da mobilidade das pessoas. Nesse contexto, coexistem interesses de diferentes atores como estados, corporações e, claro, dos próprios migrantes (CENCI, 2015).

Em se tratando de mobilidade, o conceito de brain drain refere-se à emigração internacional de longo prazo de pessoas altamente qualificadas que foram objeto de investimento educacional considerável nos seus países de origem. A questão da saída dessas pessoas implica em perdas elevadas para os países de origem, devido à importância do capital humano para o crescimento econômico. Entretanto, outros estudos discutem a questão da mobilidade de pessoas altamente qualificadas sem uma visão preconcebida de seu impacto, ou seja, sem caracterizá-la como necessariamente como perda ou ganho. Alguns países em desenvolvimento também tem conseguido atrair capital humano altamente qualificado. $\mathrm{O}$ fato dessa mobilidade de pessoas ser multifocal e multidirecional levou pesquisadores a chamar esse fenômeno de brain circulation (ZAGADI e DESAI, 2017).

Nessa linha de ideias, Saxenian (2005) realizou estudos relevantes neste campo. A autora argumenta que os mercados de trabalho globais são transformados à medida que os custos decrescentes de comunicações facilitam uma maior mobilidade e que tecnologias digitais apoiam o intercâmbio à longa distância de grandes quantidades de informações. Dessa forma, a migração internacional, historicamente um processo unidirecional, tornou-se uma opção reversível, especialmente para aqueles com habilidades técnicas escassas. Como 
resultado, cientistas e engenheiros de países em desenvolvimento, antes fadados a escolher entre morar fora de suas nações ou trabalhar em seus países de origem em atividades bem menos atraentes, passam a contribuir para suas economias domésticas, mantendo vínculos profissionais e econômicos.

Em seus estudos, Saxenian (2005) defende que os mesmos indivíduos altamente qualificados que deixaram seus países para melhores condições de vida e de trabalho no exterior iniciaram um movimento de reversão dessa "fuga de cérebros", transformando-a em uma "circulação cerebral", no momento em que voltam ao país de origem para estabelecer relações comerciais ou iniciar novos empreendimentos, enquanto mantém seus laços sociais e profissionais com o país para o qual migraram. Disto deriva o termo brain circulation. Como exemplos desses movimentos, a autora cita os investidores de risco com formação estrangeira que investem em seus países de origem ou de engenheiros e gestores que retornam a suas nações levando conhecimentos, experiências e visões de mundo adquiridas fora. Assim, formam-se verdadeiras comunidades técnicas inter-regionais capazes de fomentar e impulsionar o empreendedorismo local, utilizando-se de alianças entre profissionais, empresas e formuladores de políticas públicas.

A crescente circulação internacional de gestores, empreendedores e profissionais em geral entre países desenvolvidos e em desenvolvimento é um aspecto importante da globalização, gerando consequências para a economia global e para a sociedade em geral (BIAO, 2011; SAXENIAN, 2005). Os migrantes altamente qualificados rompem barreiras globais e ligam recursos de uma localidade a outra. Eles podem transferir habilidades de uma indústria de um país desenvolvido para clusters em um país ou região emergente. Com essas experiências, esses profissionais desenvolvem habilidades avançadas, criam redes de contatos e reputação. Organizações de países emergentes que recebem esses profissionais ganham recursos e habilidades que são localmente escassos (ZAGADI e DESAI, 2017).

Como já abordado, existem algumas abordagens para tratar dos profissionais altamente qualificados. Dos anos 2000 até a atualidade há um crescente interesse em entender o comportamento desses profissionais. Em uma das abordagens existentes, eles são chamados de trabalhadores do conhecimento, pois são aqueles que possuem alto grau de conhecimento profissional e de educação, sendo que a criação e transferência de conhecimento estão no coração de suas atividades de trabalho (DAVENPORT, 2006). Na literatura, muitos termos são usados para tratar de profissionais intensivos em conhecimento, contendo diferenças e similaridades entre si, tais como especialistas, experts, gestores e trabalhadores da informação (SURAWSKI, 2019).

Os trabalhadores do conhecimento são responsáveis por encontrar novas soluções que são capazes de influenciar o desenvolvimento dos negócios. Esses profissionais não apenas iniciam novos produtos e serviços, mas principalmente criam estratégias de negócios e o direcionamento para o seu desenvolvimento. Isto tem um valor imensurável a medida que se sabe que as organizações que operam no mercado atuam em ambientes cada vez mais complexos e turbulentos (IGIELSKI, 2017).

Outra abordagem encontrada na literatura refere-se à chamada classe criativa, que é composta por trabalhadores contemporâneos que tem uma alta capacidade de resolução de problemas, de agregar valor pela criatividade e de desenvolver novas tecnologias de produtos e processos (Surawski, 2019). O conceito foi trabalhado inicialmente pelo sociólogo Richard 
Florida (2002), trabalho que conta com larga repercussão e alto número de citações em estudos científicos de diferentes áreas do conhecimento, pois não só introduz um conceito como abre possibilidade de embasamento de inúmeros novos estudos que tenham como objeto de interesse os trabalhadores intensivos em conhecimento que são protagonistas da nova economia.

Florida (2012) qualifica a classe criativa como propulsora de desenvolvimento local, pois as mudanças da era pós-industrial alavancaram habilidades humanas inovadoras para gerar crescimento econômico. Quando se fala em classe criativa, pode-se pensar que estão sendo englobados profissionais como arquitetos, engenheiros, cientistas da computação, matemáticos, educadores, artistas, empreendedores, gestores, comunicadores e pesquisadores, entre outros.

Enquanto os membros da classe trabalhadora convencional trabalham predominantemente com seu componente físico, os membros da classe criativa trabalham principalmente com suas mentes. A principal característica que distingue a classe criativa é seus membros exercem trabalhos cuja função é criar novas formas significativas. Isso requer um alto grau de educação formal e de nível de capital humano. Pessoas desse perfil não raramente criam novos métodos e produtos extremamente úteis e de valor - sem fazer parte de suas atribuições formais de cargo. O que elas fazem regularmente é pensar por si próprias, combinar diferentes recursos e abordagens para resolver diferentes situações, exercitar elevado grau de julgamento e ainda tentar coisas radicalmente novas de tempos em tempos (FLORIDA, 2012; CHAPAIN; COMUNIAN, 2010; LENGYEL; SÁGVÁRI, 2011).

Florida (2012) traz duas classificações dentro da classe criativa, em relação às profissões das pessoas. A primeira é a de super-creative core, que inclui cientistas, engenheiros, professores universitários, poetas, artistas, arquitetos, atores e designers. Esses profissionais são capazes de produzir novas formas e produtos fortemente úteis, que gerem interesse de investimento e que possam ser manufaturados e vendidos. A segunda classificação é a de profissionais criativos, que atuam em indústrias intensivas em conhecimento, como em tecnologia da informação, serviços financeiros, gestão e negócios, aspectos legais e assistência em saúde. Eles se envolvem em resolver problemas específicos mergulhados em complexidades.

\section{Procedimentos metodológicos}

Para possibilitar o atendimento ao objetivo desta pesquisa, foi realizada uma revisão sistemática da literatura. Primeiramente, foram realizadas buscas na base de dados EBSCOHOST, em artigos científicos revisados por pares. A primeira busca utilizou a seguinte formatação e combinação de termos: human capital migration OR brain circulation OR human capital mobility, nos filtros de abstract e keywords. Já a segunda busca utilizou a seguinte configuração: creative class OR knowledge work* AND cit* OR location OR creative cit $^{*}$. Os filtros utilizados também foram abstract e keywords. Como período de investigação, foi definido o intervalo entre os anos de 2002 e 2019. Com isso, inicialmente foram identificados 64 artigos científicos para este estudo.

Após, esses artigos passaram por uma seleção em que tiveram seus resumos lidos. O critério para a seleção foi verificar a existência de relação entre fatores de atratividade urbana 
e profissionais altamente qualificados, incluindo suas diferentes nomenclaturas encontradas na literatura. Com isso, foram selecionados 30 artigos científicos para compor este estudo. Esta seleção serviu de base para a construção do modelo integrativo proposto neste artigo, em que as categorias de fatores de atratividade urbana foram propostas com base na incidência de seus itens na literatura e na proximidade de suas dimensões.

\section{Resultados}

\subsection{Fatores e categorias de análise sobre atratividade urbana para os profissionais altamente qualificados}

Quando se trata de categorias de análise sobre os fatores de atratividade de um espaço urbano - uma cidade - para os profissionais altamente qualificados, percebe-se que são considerados elementos diversos e um tanto fragmentados, embora haja incidência repetida de alguns itens na maioria das pesquisas acadêmicas. Isso resulta de estudos de diferentes pesquisadores que focam nos fatores de atratividade de uma cidade e região sob variadas lentes.

Rao e Dai (2017) utilizam em seus estudos os conceitos de tolerância social e condições de suporte a qualidade de vida. Para medir a tolerância social, são utilizados diversos indicadores, relacionados com renda familiar, educação, casamentos, raças, idiomas e orientação sexual. Em sua pesquisa, os autores utilizaram cinco aspectos para descrever a tolerância social em Xangai, na China: diversidade étnica, diversidade de educação, diversidade de renda, diversidade de estado civil e diversidade de local de nascimento. A fonte de dados utilizada pelos pesquisadores foi o Censo populacional.

Já as condições de suporte à qualidade de vida denotam sobre as condições físicas do espaço urbano, de moradia, cuidados médicos e instituições de ensino. Rao e Dai (2017) utilizam em seus estudos 8 domínios para medir essas condições: oportunidades de emprego, assistência médica, instalações educacionais, comutação, recursos alimentares, habitação, lazer e amenidades naturais. Diferentes fontes de dados e indicadores são utilizados para realizar essas medidas. Como exemplo, foram levantados o número de hospitais de ponta, hospitais de referência e postos de saúde nos espaços urbanos investigados. Para a educação, o número de escolas de ensino fundamental e médio, o número de escolas secundárias e o número de faculdades e universidades. Para os recursos alimentares, foram levantados números de restaurantes, supermercados, lojas de alimentos frescos e lojas de conveniência. $\mathrm{E}$ para o domínio de lazer são utilizados dados do número de academias, clubes de entretenimento, cafés, praças públicas e zoológicos.

Nessa mesma esteira de conhecimento, Khoo et. al. (2017) desenvolveram uma escala do tipo Likert para indicadores referentes à qualidade local na cidade de Penang, na Malásia. A escala contempla elementos que visam medir questões de condições de criatividade, diversidade cultural e pessoal, vida em comunidade, vibração da vida nas ruas, clima de negócios, entre outros. Os autores também sugerem cinco dimensões ao monitorar fatores de atratividade de uma cidade criativa: talentos, tecnologia, educação, infraestrutura e liderança.

Szczech (2014) argumenta ser a criatividade urbana influenciada por fatores como: políticas públicas, diversidade e expressão, abertura e confiança, empreendedorismo e 
inovação, liderança e visão, desenvolvimento de talentos, comunicação e redes, bem-estar e profissionalismo. O autor buscou estudar o potencial criativo de cidades polonesas, comparando-as com outras cidades europeias. Ele propôs alguns indicadores como o percentual de empregados em manufatura de produtos de inovação, ciência e tecnologia, proporção de empresas locais que produzem produtos de inovação, ciência e tecnologia e número de estudantes com ensino superior a cada 100 habitantes da população local.

Chapain e Comunian (2010) sugerem quatro dimensões inter-relacionadas de suporte à economia criativa local: infraestrutura, governança, infraestrutura soft e mercados. Já Acs e Megyesi (2009) ressaltam o que chamam de 4 "T's" do desenvolvimento econômico local: talento, tolerância, tecnologia e território. Essa abordagem deriva também dos trabalhos de Florida (2012) que aborda 3 "T's" (talento, tolerância e tecnologia). Sendo assim, Acs e Megyesi (2009) acrescentam mais um elemento - território - para nortear indicadores de nível de criatividade em cidades e regiões metropolitanas. Seus estudos foram aplicados na cidade de Baltimore, nos Estados Unidos.

Para a dimensão de talento, Acs e Megyesi (2009) utilizaram medidas baseadas em dados de censo sobre demografia, educação e ocupação da população. Analisaram questões sobre nível educacional da população de 25 a 34 anos, a migração de pessoas morando há mais de 5 anos na região e dados sobre população estrangeira na cidade. Já para a dimensão tolerância - que também poderia ser chamada de diversidade - os autores se utilizam de índices especialmente relacionados à diversidade sexual e de cultura boêmia. No que diz respeito à dimensão de tecnologia - na qual a questão da inovação está atrelada - as medidas tomam por base as atividades relacionadas a patentes e o compartilhamento de alta tecnologia. Os autores salientam que as patentes são uma medida imperfeita, porém, são as melhores disponíveis para pesquisa quando se trata de mudança tecnológica. Por fim, a dimensão território - que engloba as facilidades urbanas - faz uso dos índices de desigualdade de renda e de condições de habitação.

Lorenzen e Andersen (2012) também relatam em sua pesquisa fatores sobre tolerância e serviços. Eles citam correlações que foram calculadas entre o crescimento de profissionais altamente qualificados na Dinamarca e esses fatores. São utilizadas cinco dimensões de indicadores: oportunidades culturais, nível de serviço público, presença de estrangeiros no país, inclusão social de imigrantes não ocidentais e incidência de força de trabalho em áreas de lazer. Dentro dessas dimensões, são medidas questões como número de empregados em restaurantes, bares, clubes e entretenimentos; número de parques, museus e atividades culturais; número de professores públicos, profissionais de saúde e assistência social por 1.000 habitantes; incidência de estrangeiros vivendo no país; e taxa de emprego de habitantes não ocidentais.

\subsection{Esquema conceitual e integrativo}

Ao se percorrer a literatura acadêmica no que se refere à utilização de fatores de atratividade de cidades e regiões para profissionais altamente qualificados, percebe-se a alta diversificação de seu uso, dificultando comparações entre resultados e abrindo uma lacuna de pesquisa que este artigo busca contemplar. Dessa forma, é trazida uma proposta integrativa dos fatores de atratividade, procurando-se contribuir com as pesquisas em mobilidade de 
capital humano e cidades. São, portanto, propostas quatro principais categorias de fatores de atratividade urbana: tolerância social, qualidade de vida, ambiente de empreendedorismo e inovação e educação.

Sobre a questão da tolerância social, esta se constitui em aspecto bastante relevante para os trabalhadores do conhecimento. Com a mobilidade consequente da alta formação e nível educacional desses profissionais, surge também a demanda por encontrar localidades que acolham e aceitem adequadamente os migrantes. Portanto, cidades com resistência ou nível baixo de aceitação a migrantes estão fadadas a perder competitividade na busca por talentos (RAO e DAI, 2017; FLORIDA, 2012). Por outro lado, se a cidade consegue acolher as pessoas e ainda conviver com a diversidade, aumentam-se as chances de atrair e reter talentos ricos em conhecimentos e também em cultura. Portanto, indicadores como incidência de estrangeiros habitantes no local e número de casamentos entre pessoas de diferentes raças são exemplos que podem ser bons indicativos de tolerância social de uma cidade. Movimentos culturais locais também podem ser usados como reforços para a tolerância social, sinalizando para os migrantes a mensagem de uma cidade hospitaleira e receptiva.

Outra categoria de fatores proposta é em relação à qualidade de vida. Os indicadores que compõem esta categoria são os mais frequentes na literatura (CHAPAIN e COMUNIAN, 2010; SZCZECH, 2014). Como profissionais que atuam em ambiente urbano, é natural pensar-se que os trabalhadores do conhecimento valorizam fortemente os aspectos de qualidade de vida local. Esta categoria é aquela que abarca a maior amplitude de indicadores, o que enseja que nela estarão os esforços mais complexos de formuladores de políticas locais de atratividade, visto que sua natureza envolve questões de saúde, segurança, lazer, mobilidade e outras. Para aqueles que podem planejar onde querem morar e trabalhar, o conjunto dos aspectos de qualidade de vida impacta na decisão de moradia, pois são aspectos que serão notados no cotidiano dos habitantes de uma cidade. Desde o tempo de deslocamento ao trabalho até as opções de lazer e restaurantes da cidade são elementos que são de interesse direto de moradores com perfil educacional e cultural elevado. Portanto, os fatores de qualidade de vida devem receber especial atenção nas cidades.

O ambiente de empreendedorismo e inovação compõe outra categoria de fatores de atratividade proposta neste estudo. Esta categoria se mostra importante a medida que as oportunidades aos profissionais altamente qualificados principalmente ocorrem em ambientes que operam baseados em produção intensiva de conhecimento (IGIELSKI, 2017). Para que as indústrias baseadas em conhecimento consigam operar e prosperar, é preciso que o ambiente local estimule e contribua para o seu funcionamento. Isso ocorre quando há uma preocupação com os ecossistemas de empreendedorismo e inovação. Essa categoria influencia diretamente não só no desenvolvimento local, mas na oportunidade de postos de trabalho para profissionais com alta qualificação, uma vez que se forma um ciclo que se retroalimenta: quanto melhor for o ambiente de empreendedorismo e inovação, mais pessoas qualificadas serão atraídas. E quanto maior a concentração de capital humano altamente qualificado na cidade, maior tende ser a dinâmica local de empreendedorismo e inovação.

A última categoria proposta refere-se aos aspectos de nível educacional. Os profissionais altamente qualificados estão em constante formação, não há espaço para interrupções no processo educacional para quem trabalha com informação e conhecimentos em constantes mudanças na nova economia. Sendo assim, as cidades precisam identificar a 
amplitude de acesso à formação e conhecimento no seu território. Entretanto, uma limitação encontrada nos fatores desta categoria parece ser a questão da qualidade do ensino. Os pesquisadores tem utilizado aspectos sobre o número de estabelecimentos de ensino, professores e estudantes. Porém, isto não contempla necessariamente uma resposta se a qualidade das instituições de ensino permite uma real qualificação da população para atuar na economia baseada em conhecimento. A utilização de fatores que permitam que se realize essa avaliação tem sido negligenciada.

$\mathrm{Na}$ sequência, segue quadro que sumariza as categorias propostas e analisadas neste estudo, proporcionando uma visão integradora no que diz respeito aos fatores urbanos de atratividade e retenção de profissionais altamente qualificados.

Quadro 1: Proposta de categorização de fatores de atratividade urbana a profissionais altamente qualificados

\begin{tabular}{|c|c|c|c|}
\hline Categoria & Dimensões & Indicadores & Referências \\
\hline Tolerância social & $\begin{array}{l}\text { Diversidade e expressão. } \\
\text { Casamentos, raças, idiomas, } \\
\text { renda familiar, orientação } \\
\text { sexual. }\end{array}$ & $\begin{array}{l}\text { Renda média familiar, } \\
\text { número de pessoas } \\
\text { homossexuais, } \\
\text { casamentos entre } \\
\text { pessoas de diferentes } \\
\text { raças, diversidade de } \\
\text { local de nascimento. } \\
\text { Incidência de } \\
\text { estrangeiros } \\
\text { habitantes no local; } \\
\text { taxa de emprego de } \\
\text { estrangeiros no local; }\end{array}$ & $\begin{array}{l}\text { Rao e Dai (2017). } \\
\text { Szczech (2014). } \\
\text { Lorenzen e Andersen } \\
\text { (2012). }\end{array}$ \\
\hline Qualidade de vida & $\begin{array}{l}\text { Facilidades urbanas. } \\
\text { Governança e Infraestrutura. } \\
\text { Assistência médica, } \\
\text { instalações educacionais, } \\
\text { recursos de alimentação, } \\
\text { oportunidades de emprego, } \\
\text { habitação e lazer. }\end{array}$ & $\begin{array}{l}\text { Número de hospitais e } \\
\text { postos de saúde, } \\
\text { número de escolas } \\
\text { públicas, número de } \\
\text { restaurantes e lojas de } \\
\text { conveniência, número } \\
\text { de academias e } \\
\text { clubes, número de } \\
\text { cafés e praças } \\
\text { públicas. }\end{array}$ & $\begin{array}{l}\text { Rao e Dai (2017). } \\
\text { Szczech (2014). } \\
\text { Chapain e Comunian } \\
\text { (2010). } \\
\text { Khoo et. al. (2017). }\end{array}$ \\
\hline $\begin{array}{l}\text { Ambiente de } \\
\text { empreendedorismo e } \\
\text { inovação }\end{array}$ & $\begin{array}{l}\text { Ecossistema de } \\
\text { empreendedorismo e } \\
\text { inovação. Patentes e } \\
\text { compartilhamento de alta } \\
\text { tecnologia. Clima e } \\
\text { oportunidades de negócios. }\end{array}$ & $\begin{array}{l}\text { Percentual de } \\
\text { empregados em } \\
\text { manufatura de } \\
\text { produtos de inovação, } \\
\text { ciência e tecnologia; } \\
\text { percentual de } \\
\text { empresas locais que } \\
\text { produzem produtos de } \\
\text { inovação, ciência e } \\
\text { tecnologia. }\end{array}$ & $\begin{array}{l}\text { Szczech (2014). } \\
\text { Khoo et. al. (2017). }\end{array}$ \\
\hline Educação & $\begin{array}{l}\text { Educação e ocupação da } \\
\text { população. }\end{array}$ & $\begin{array}{l}\text { Nível educacional da } \\
\text { população de } 25 \text { a } 34 \\
\text { anos. Número de } \\
\text { estudantes com ensino } \\
\text { superior a cada } 100\end{array}$ & $\begin{array}{l}\text { Acs e Megiesy (2009). } \\
\text { Khoo et. al. (2017). } \\
\text { Rao e Dai (2017). }\end{array}$ \\
\hline
\end{tabular}




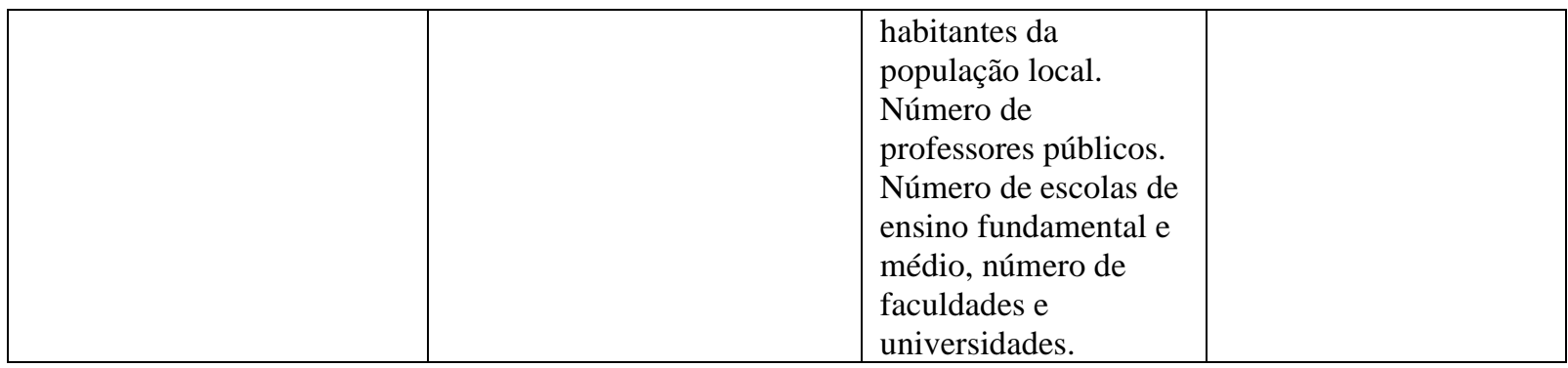

Fonte: elaborado pelos autores.

\section{Considerações finais}

Este artigo teve por objetivo propor um modelo integrador contendo categorias de fatores de atratividade urbana para profissionais altamente qualificados. Primeiramente, buscou-se conhecer quais são os principais fatores de atratividade urbana de profissionais com capital humano altamente qualificado abordados na literatura. Com isso, o artigo realizou uma proposta integradora de categorias de fatores de atratividade, desempenhando uma análise quanto a essas categorias. Elas envolvem a tolerância social, a qualidade de vida, o ambiente de empreendedorismo e inovação e a educação.

Dos trabalhos que suportam este estudo, a maior parte dos artigos aplica pesquisas teórico-empíricas predominantemente em países europeus, o que sugere uma lacuna de estudos aplicados em realidades de países emergentes, que igualmente precisam alavancar seus índices de empreendedorismo, inovação e atividades ligadas ao conhecimento.

Em relação aos fatores e categorias de análise pesquisados, percebe-se que para os profissionais altamente qualificados as questões como tolerância, diversidade, abertura e cultura realmente são elementos-chave e são encontradas na grande maioria dos estudos empíricos, traduzidas em indicadores palpáveis para medi-las em cidades e regiões. Os estudos apresentam alguma variação em como essas questões são medidas, mas elas estão geralmente presentes nessas pesquisas. Da mesma forma, elementos relativos à qualidade de vida como saúde e educação também são relevantes. Alguns estudos tentam contemplar o máximo de dimensões possíveis, enquanto outros focam em algumas poucas dimensões e as exploram de forma mais específica. $\mathrm{O}$ campo de pesquisa parece ter tido o seu auge na década de 2000, em que são encontrados o maior número de artigos. Mesmo assim, as questões referentes ao tema ainda geram interesse na comunidade acadêmica.

Como limitações do estudo, pode-se considerar que alguns artigos contendo a utilização de fatores de atratividade urbana possam ter ficado de fora da pesquisa, devido a critérios de busca utilizados. Da mesma forma, as abordagens de trabalhadores do conhecimento e profissionais criativos não são as únicas nomenclaturas usadas para tratar de profissionais altamente qualificados, visto que a literatura também utiliza alguns outros termos, embora em menor frequência.

Futuras pesquisas poderiam utilizar o modelo integrador proposto neste artigo para verificar empiricamente se essas categorias de fatores se aplicam adequadamente ao estudo de atratividade de cidades aos profissionais altamente qualificados em contextos específicos, como, por exemplo, cidades de países em desenvolvimento, tendo em vista que na literatura predominam estudos em países europeus, asiáticos e norte-americanos. 


\section{REFERÊNCIAS}

ACS, Zoltan J.; MEGYESI, Monika I. Creativity and industrial cities: A case study of Baltimore. Entrepreneurship and Regional Development, v. 21, n. 4, p. 421-439, 2009.

BECKER, G. S. Investment in human capital: A theoretical analysis. The Journal of Political Economy, p. 9-49, 1962.

BIAO, Xiang. A ritual economy of 'talent': China and overseas Chinese professionals. Journal of Ethnic and Migration Studies, v. 37, n. 5, p. 821-838, 2011.

BREINER, Jonathan M. et al. What is STEM? A discussion about conceptions of STEM in education and partnerships. School Science and Mathematics, v. 112, n. 1, p. 3-11, 2012.

CASTELLS, Manuel. A sociedade em rede. A era da Informação: Economia. Sociedade e Cultura, v. 1, p. 5, 1999.

CENCI, Alessandra. A "capability view" on migration: some theoretical issues raised by the Southern Euro Zone highly skilled mobility. Innovation: The European Journal of Social Science Research, v. 28, n. 4, p. 443-463, 2015.

CHAPAIN, Caroline; COMUNIAN, Roberta. Enabling and inhibiting the creative economy: The role of the local and regional dimensions in England. Regional studies, v. 44, n. 6, p. 717-734, 2010.

DAVENPORT, Thomas H. Thinking for a living: how to get better performances and results from knowledge workers. Harvard Business Press, 2005.

ENGEL, Jerome S.; BERBEGAL-MIRABENT, Jasmina; PIQUÉ, Josep M. The renaissance of the city as a cluster of innovation. Cogent Business \& Management, v. 5, n. 1, p. $1532777,2018$.

FELIN, Teppo.; ZENGER, Todd R.; TOMSIK, Joshua. The knowledge economy: emerging organizational forms, missing microfoundations, and key considerations for managing human capital. Human Resource Management Journal. Vol. 48, n. 4, p. 555-570, 2009.

FELSENSTEIN, Daniel. Factors affecting regional productivity and innovation in Israel: Some empirical evidence. Regional Studies, v. 49, n. 9, p. 1457-1468, 2015.

FLORIDA, Richard. The rise of the creative class. New York: Basic books, 2002.

FLORIDA, Richard. The rise of the creative class: revisited. New York: Basic books, 2012.

IGIELSKI, Michał. Assumptions to the model of managing knowledge workers in modern organizations. Management, v. 21, n. 1, p. 133-147, 2017.

KEHOE, R. R. TZABBAR, D. Lighting the way or stealing the shine? an examination of the duality in star scientists' effects on firm innovative performance. Strategic Management Journal. Published online, 2014.

KHOO, Suet Leng et al. How possible is a creative city in Penang? An analysis of architects' perceptions about creativity and quality of place. Creative Industries Journal, v. 10, n. 1, p. 3-20, 2017.

LENGYEL, Balázs; SÁGVÁRI, Bence. Creative occupations and regional development in Hungary: mobility of talent in a one-centred transition economy. European Planning Studies, v. 19, n. 12, p. 2073-2093, 2011. 
LORENZEN, Mark; ANDERSEN, Kristina Vaarst. Different creative cities: Exploring Danish data to adapt the creative class argument to small welfare economies. Creative Industries Journal, v. 4, n. 2, p. 123-136, 2012.

NIKOLOPOULOS, Kanellos-Panagiotis; DANA, Leo-Paul. Social capital formation in EU ICT SMEs: the role played by the mobility of knowledge workers. European Management Review, v. 14, n. 4, p. 409-422, 2017.

ONKELIX, J. MANOLOVA, T. S. EDELMAN, L. F. The human factor: Investments in employee human capital, productivity, and SME internationalization. Journal of International Management. 2016.

RAO, Yingxue; DAI, Deyi. Creative class concentrations in Shanghai, China: What is the role of neighborhood social tolerance and life quality supportive conditions?. Social Indicators Research, v. 132, n. 3, p. 1237-1246, 2017.

ROSA, Newton Braga; DE SOUZA, Yeda Swirski. The role of cities in decentralization of national policies on science, technology and innovation. Sinergie, v. 105, n. Jan-Apr, 2018.

SASSEN, Saskia. Cities today: A new frontier for major developments. The Annals of the American Academy of Political and Social Science, v. 626, n. 1, p. 53-71, 2009.

SAXENIAN, AnnaLee. From Brain Drain to Brain Circulation: Transnational Communities and Regional Upgrading in India and China. Studies in Comparative International Development. Vol. 40, n. 2, p. 35-61, 2005.

SCHULTZ, Theodore W. Investment in human capital. The American Economic Review, p. $1-17,1961$.

SHAPIRO, Jesse M. Smart cities: quality of life, productivity, and the growth effects of human capital. The review of economics and statistics, v. 88, n. 2, p. 324-335, 2006.

STANKOVIC, Mirjana et al. Brain circulation and spatial mobility of knowledge in Southeast Europe. The International Journal of Management Science and Information Technology (IJMSIT), n. 13, p. 15-41, 2014.

SOFRONIJEVIĆ, Adam; MILIĆEVIĆ, Vesna; ILIĆ, Bojan. Smart city as framework for creating competitive advantages in international business management. Management: Journal of Sustainable Business and Management Solutions in Emerging Economies, v. 19, n. 71, p. 5-15, 2014.

SZCZECH, Ewelina et al. Is there a creative city in poland? Defining and measuring the concept in Poland. Prace Naukowe Uniwersytetu Ekonomicznego we Wroclawiu, n. 334, p. 242-251, 2014.

SURAWSKI, Bartosz. Who is a "knowledge worker"-clarifying the meaning of the term through comparison with synonymous and associated terms. Management, v. 23, n. 1, p. 105-133, 2019.

THITE, Mohan. Smart cities: implications of urban planning for human resource development. Human Resource Development International, v. 14, n. 5, p. 623-631, 2011.

TSENG, C. Y., \& GOO, Y. J. J. Intellectual capital and corporate value in an emerging economy: Empirical study of Taiwanese manufacturers. R\&D Management. Vol 35(2), p. 187-201, 2005.

WEISS, MARC A. Metropolitan economic strategy: the key to prosperity. Harvard College Economics Review, v. 1, n. 1, p. 25-27, 2006. 
ZAGADE, Aatish; DESAI, Supriya P. Brain drain or brain circulation: A study of returnee professionals in India. Journal of Commerce and Management Thought, v. 8, n. 3, p. 422, 2017.

ZHAO, Shuming. Application of human capital theory in China in the context of the knowledge economy. The International Journal of Human Resource Management. Vol. 19:5, p. 802-817, 2008. 